\title{
Medical Expulsive Therapy (MET) for Large Distal Ureteral Stones: A Prospective Study Comparing Three Drugs
}

\author{
Mourad Dali Khereddine1, Traore Mamadou Tiéoulé2*, Kacem Aziz¹, Chaker Kays, \\ Ben Rhouma1, Sellami Ahmed', Nouira Yassine1 \\ ${ }^{1}$ Service d'urologie de Hospital la Rabta, Tunis, Tunisia \\ ${ }^{2}$ Service d'urologie de l'Hôpital de Ouahigouya, Ouahigouya, Burkina Faso \\ Email: bechakmddd@gmail.com, *t.mamadou.t@gmail.com, azizkacem7@gmail.com, chakerkays@gmail.com, \\ sbenrhouma@yahoo.fr, sellamiahmed@yahoo.fr, nouirayassine@gmail.com
}

How to cite this paper: Khereddine, M.D., Tiéoulé, T.M., Aziz, K., Kays, C., Rhouma, B., Ahmed, S. and Yassine, N. (2020) Medical Expulsive Therapy (MET) for Large Distal Ureteral Stones: A Prospective Study Comparing Three Drugs. Open Journal of Urology, 10, 152-157.

https://doi.org/10.4236/oju.2020.105017

Received: March 4, 2020

Accepted: May 4, 2020

Published: May 7, 2020

Copyright $\odot 2020$ by author(s) and Scientific Research Publishing Inc. This work is licensed under the Creative Commons Attribution International License (CC BY 4.0).

http://creativecommons.org/licenses/by/4.0/

(c) (i) Open Access

\begin{abstract}
Introduction: One of the most common disorders of the urinary tract is Urolithiasis. Twenty percent of lithiasis are located in the ureter of which $68 \%$ are seen in the distal ureter. The concept of medical expulsive therapy (MET) has been developed with enough knowledge of the ureter physiology in order to make easier the spontaneous expulsion of the stone. The aim of this study was to evaluate the efficacy and safety of three different drugs for the treatment of pelvic ureteral stones. Materiel and Methods: Between October 2017 and November 2018, 90 adult patients presenting with low or non-obstructive pelvic ureteral stones sized 8 to $10 \mathrm{~mm}$ were included. They were prospectively randomized, using computer-based randomization charts, into three equal groups: treatment with ketoprofen $100 \mathrm{mg}$ once daily (Group I), silodosin $8 \mathrm{mg}$ once daily (Group II) and tadalafil $5 \mathrm{mg}$ once daily (Group III). The aim was to compare spontaneous expulsion of stone between those drugs Results: The mean expulsion time from the start of MET was $11.5 \pm 3.27$ days for ketoprofen group, $10.71 \pm 3.98$ days for silodosin group and $10.57 \pm 3.40$ days for tadalafil group. But these differences were also not significant $(\mathrm{P}=$ 0.79). The use of analgesics (grade II) was higher in groups II and III compared to group I, but without significant difference $(23.33 \%$ in group I, $33.33 \%$ in group II and $40 \%$ in group III, $\mathrm{p}=0.38$ ). Discussion: The overall chance of spontaneous passage is low when the stone diameter is sized more than $7 \mathrm{~mm}$. A wide range of spontaneous passage rates have been reported in the literature, varying from $71 \%$ to $98 \%$ for distal ureteral stones less than 5 $\mathrm{mm}$ and $25 \%-53 \%$ for stone sized 5 to $10 \mathrm{~mm}$ with a mean expulsion time of more than 10 days. Conclusion: The three drugs have a low expulsion rate
\end{abstract}


for 8,9 and $10 \mathrm{~mm}$ pelvic ureteral stones with a higher adverse event rate for the NSAID group.

\section{Keywords}

Expulsive Therapy, Ureteral Stones, Drugs

\section{Introduction}

One of the most common disorders of the urinary tract is Urolithiasis. The world prevalence of stone disease has been estimated at $10 \%$ to $15 \%$ [1]. Twenty percent of lithiasis are located in the ureter of which $68 \%$ are seen in the distal ureter [2]. The most effective treatment modality depends on several factors such as size, location and composition of the stone, severity of obstruction, symptoms, and anatomy of the urinary system.

Proposed treatments for ureteral calculi are observation, medical expulsive therapy, extracorporeal shock wave and lithotripsy (ESWL), retrograde ureterorenoscopy, antegrade percutaneous ureterorenoscopy, and laparoscopic and open ureterolithotomy [3].

The possibility of spontaneous expulsion of the ureteral calculi depends on two factors: the size of the calculi and its anatomic location. According to a meta-analysis, the rate of spontaneous expulsion of the stones smaller than $5 \mathrm{~mm}$ is approximately $70 \%$ while it is $47 \%$ for the stones between 5 and $10 \mathrm{~mm}$ [4]. When we consider the anatomic location of the stone, we find that $71 \%$ of the distal ureteral calculi and $22 \%$ of the proximal ureteral calculi expulse spontaneously [5]. The concept of medical expulsive therapy (MET) has been developed with enough knowledge of the ureter physiology in order to make easier the spontaneous expulsion of the stone.

Several studies have been evaluated as MET, including: corticosteroid, nonsteroidal anti-inflammatory drug (NSAID), calcium-channel blocker, $\alpha$-adrenergic blockers and, more recently, the phosphodiesterase type 5 inhibitors (PDE5i). Moreover, MET may reduce medical costs and avoid unnecessary surgeries and they associated risks and complications. In current practice, MET has been shown to increase the stone passage rates of moderately sized ureteral stones. However, until now, the efficacy of MET in the expulsion of lower ureteral stones (LUS) larger than $7 \mathrm{~mm}$ has been evaluated in some studies and the results were discordant. For these reasons, we conducted a prospective randomized study to evaluate the efficacy and safety of three different drugs for the treatment of pelvic ureteral stones sized: 8,9 and $10 \mathrm{~mm}$.

\section{Materiel and Methods}

Between October 2017 and November 2018, 90 adult patients (>18 years of age) presenting with low or non-obstructive (grade I - II hydronephrosis) pelvic ure- 
teral stones sized 8 to $10 \mathrm{~mm}$ were included. They were prospectively randomized, using computer-based randomization charts, into three equal groups: treatment with ketoprofen $100 \mathrm{mg}$ once daily (Group I), silodosin $8 \mathrm{mg}$ once daily (Group II) and tadalafil $5 \mathrm{mg}$ once daily (Group III). An informed and written consent was taken from each patient before enrolment into the study. Ethical clearance was taken from the institutional ethics committee. Stone size (largest transverse diameter) was measured on non-contraste computed tomography scan.

The exclusion criteria were: patients with solitary kidney, history of previous surgery on same ureter, double J stent, deteriorating renal function, fever, grade III or IV hydronephrosis, acute or chronic renal failure, multiple ureteral stones, a location stone other than pelvic ureter, allergy to NSAID, silodosin or tadalafil, concomitant treatment with $\alpha$-blockers, calcium antagonists, or nitrates, pregnant or lactating mothers, patients who demanded urgent stone removal.

Therapy was given for a maximum of 4 weeks. The primary end point was the expulsion rate. Time to stone expulsion, analgesic use, number of hospital visits for pain, and adverse effects of the drugs were noted. Statistical analyses were done using Fisher's exact test and Chi-square test. P-value $<0.05$ was considered to be statistically significant.

\section{Results}

A total of 90 patients were included in the study and randomized into three equal groups of 30 patients each. All patients completed the study except three who presented acute pyelonephritis during the 4 weeks of evaluation: two patients from group I and one patient from group III $(p=0.463)$. No statistically significant differences were observed regarding the age, sex, and stone size distribution of patients between both groups (Table 1).

The expulsion rate was $22.22 \%$ overall and no significant difference was found for stone clearance rate between both groups (Group I-20\%, Group II23.33\%, Group III-23.33\%, P = 0.93) (Table 2).

The mean expulsion time from the start of MET was $11.5 \pm 3.27$ days for ketoprofen group, $10.71 \pm 3.98$ days for silodosin group and $10.57 \pm 3.40$ days for tadalafil group. But these differences were also not significant $(P=0.79)$ (Table 2).

Table 1. Patients and stone characteristics according to groups.

\begin{tabular}{ccccc}
\hline & $\begin{array}{c}\text { Group I = Ketoprofen } \\
(\mathrm{n}=30)\end{array}$ & $\begin{array}{c}\text { Group II }=\text { Silodosin } \\
(\mathrm{n}=30)\end{array}$ & $\begin{array}{c}\text { Group III }=\text { Tadalafil } \\
(\mathrm{n}=30)\end{array}$ & p-value \\
\hline Age (mean \pm SD) & $42.27 \pm 10.66$ & $43.03 \pm 12.42$ & $45.2 \pm 12.94$ & 0.772 \\
$\begin{array}{c}\text { Gender (male/female) } \\
\text { Stone size (mm) } \\
(\text { mean } \pm \text { SD) }\end{array}$ & $17 / 13$ & $20 / 10$ & $16 / 14$ & 0.551 \\
Side (right/left) & $8.76 \pm 1.18$ & $8.93 \pm 1.07$ & $9.14 \pm 0.82$ & 0.805 \\
\hline
\end{tabular}


Table 2. Results of the three groups.

\begin{tabular}{ccccc}
\hline & $\begin{array}{c}\text { Group I = Ketoprofen Group II = Silodosin Group III = Tadalafil } \\
(\mathrm{n}=30)\end{array}$ & $(\mathrm{n}=30)$ & $\mathrm{p}$-value \\
& 20 & 23.33 & 23.33 & 0.93 \\
\hline Expulsion rate (\%) & & & & \\
$\begin{array}{c}\text { Mean expulsion } \\
\text { time } \pm \text { SD (days) }\end{array}$ & $11.5 \pm 3.27$ & $10.71 \pm 3.98$ & $10.57 \pm 3.40$ & 0.79 \\
$\begin{array}{c}\text { Use of grade II } \\
\text { analgesics (\%) }\end{array}$ & 23.33 & 33.33 & 40 & 0.551 \\
\hline
\end{tabular}

The use of analgesics (grade II) was higher in groups II and III compared to group I, but without significant difference $(23.33 \%$ in group I, 33.33\% in group II and $40 \%$ in group III, $\mathrm{p}=0.38$ ) (Table 2).

No serious side effects were noted, but a higher rate of adverse events was observed in the NSAID group (26.66\% in group I, $13.33 \%$ in group II and $10 \%$ in group III, $p=0.18$ ). Nausea and epigastralgia were the most common side effects in the ketoprofen group.

\section{Discussion}

Of all urinary tract stones, $20 \%$ are located in the ureter, of which $70 \%$ are located in its distal portion [2]. It is estimated that $95 \%$ of stones up to $4 \mathrm{~mm}$ pass spontaneously within 40 days [4]. A meta-analysis by the AUA guidelines panel showed that ureteral stones sized less than $5 \mathrm{~mm}$ will pass up to $98 \%$ of cases. The overall chance of spontaneous passage is low when the stone diameter is sized more than $7 \mathrm{~mm} \mathrm{[6]} \mathrm{[7].} \mathrm{A} \mathrm{wide} \mathrm{range} \mathrm{of} \mathrm{spontaneous} \mathrm{passage} \mathrm{rates} \mathrm{have}$ been reported in the literature, varying from $71 \%$ to $98 \%$ for distal ureteral stones less than $5 \mathrm{~mm}$ and $25 \%-53 \%$ for stone sized 5 to $10 \mathrm{~mm}$ with a mean expulsion time of more than 10 days [4] [5].

Due to the risk of renal damage, most authors recommend that stone passage should not exceed 4 - 6 weeks [7]. Patients with prolonged partial ureteral obstruction ( $>4-6$ weeks), persisting pain or urinary tract infection are less eligible to conservative management. Therefore, observation is allowed only for informed patients without complications (infection, refractory pain, deterioration of renal function).

Many therapies have been tested as METs including NSAID, alpha blockers, calcium channel blockers, corticosteroids, and most recently PDE5i. But only the Alpha blockers are currently recommended for use as MET by the EAU [8].

The a-antagonist contraction inhibition of ureteral smooth muscle represents the pathophysiologic basis for medical expulsive therapy. It results in less severe ureterospasm, which eases the stone passage. The distal ureter has the highest density of a1-adrenergic receptors [9].

Thus, distal ureteral stones should benefit most from medical expulsive therapy. Due to the high probability of spontaneous passage of stones down to 5 $\mathrm{mm}, \mathrm{MET}$ is less likely to increase the stone-free rate in these cases [10].

Actually, because of conflicting results from recent meta-analyses and large 
randomized controlled trials, the efficacy of MET in large stones is unclear.

MET had been widely used until the release of the Spontaneous Urinary Stone Passage Enabled by Drugs (SUSPEND) trial. This large, multicenter, randomized controlled trial by Pickard et al. [11] revealed that tamsulosin was not superior to placebo in decreasing intervention rates to clear ureteral stone. The trial used the need for urologic intervention as the main outcome measure. Since that study, medical expulsive therapy has been compromised.

New multicenter, randomized, double blind, placebo-controlled trials were performed to elucidate the discrepancies between some meta-analyses of mostly small trials [12] [13] and a high-quality randomized controlled trial. A randomized controlled trial by Furyk et al. [14] including 403 patients, found no benefits of medical expulsive therapy with tamsulosin for patients with distal ureteral stones. However, the subgroup of patients with stones of 5 to $10 \mathrm{~mm}$ had an increased rate of expulsion.

Also, Meltzer et al. [15] in their randomized study including 512 patients with ureteral stones between 1 and $8 \mathrm{~mm}$, didn't find a difference in stone passage rates between patients treated with tamsulosin compared with placebo $(52 \%$ versus $49 \%)$.

More recent, large prospective randomized trial [16] had compared tamsulosin with placebo for 4 to $7 \mathrm{~mm}$ distal ureteral stones in greater in a population of 3200 patients. The results were similar to those of the Meltzer and al trial: there is no difference for stones $5 \mathrm{~mm}$ or less and an increase in stone passage in the group with 5.1 - to $7-\mathrm{mm}$ stones ( $87 \%$ versus $75 \%$ ), with a small overall benefit when all sizes were considered ( 4 to $7 \mathrm{~mm} ; 86 \%$ versus $79 \%$ ).

In our study, although the number of patients was poor, we compared the three most used MET to treat large distal ureteral stones $(8,9$ and $10 \mathrm{~mm})$. The expulsion rate was globally low (22.22\%) and no significant difference was found for stone clearance rate between both groups. Also, three of our patients ( $4 \%)$ developed acute pyelonephritis during the four weeks of treatment.

Therefore, we decided to discontinue this study and to treat in a faster way using endoscopic procedure patients presenting this kind of stones.

\section{Conclusion}

The three drugs tried (tamsulosin, silodosin and tadalafil) have a low expulsion rate for 8,9 and $10 \mathrm{~mm}$ pelvic ureteral stones with a higher adverse event rate for the NSAID group. More invasive intervention should be performed as early as possible for this type of calculi.

\section{Conflicts of Interest}

The authors declare no conflicts of interest regarding the publication of this paper.

\section{References}

[1] Khan, S.R., Pearle, M.S., Robertson, W.G., et al. (2016) Kidney Stones. Nature Re- 
views Disease Primers, 2, Article No. 16008. https://doi.org/10.1038/nrdp.2016.8

[2] Carstensen, H.E. and Hansen, T.S. (1973) Stones in the Ureter. Acta Chirurgica Scandinavica. Supplementum, 433, 66-71.

[3] Ergun, O. and Gonen, M. (2014) Ürinersiste mtashastalıgın damedikaleks pulsiftedavi: Kime, nasil, ne kadar? Endoürolojibülteni, 7, 74-76. https://doi.org/10.5350/ENDO2014070206

[4] Preminger, G.M., Tiselius, H.G., Assimos, D.G., et al. (2007) EAU/AUA Nephrolithiasis Guideline Panel. 2007 Guideline for the Management of Ureteral Calculi. Journal of Urology, 178, 2418-2434. https://doi.org/10.1016/j.juro.2007.09.107

[5] Morse, R.M. and Resnick, M.I. (1991) Ureteral Calculi: Natural History and Treatment in an Era of Advanced Technology. Journal of Urology, 145, 263-265. https://doi.org/10.1016/S0022-5347(17)38310-6

[6] Ibrahim, A.I., Shetty, S.D., Awad, R.M. and Patel, K.P. (1991) Prognostic Factors in the Conservative Treatment of Ureteric Stones. British Journal of Urology, 67, 358-361.

https://doi.org/10.1111/j.1464-410X.1991.tb15161.x

[7] Tiselius, H.G., Ackermann, D., Alken, P., Buck, C., Conort, P., Gallucci, M., et al. (2001) Guidelines on Urolithiasis. European Urology, 40, 362-371. https://doi.org/10.1159/000049803

[8] Turk, C., Knoll, T. and Petrik, A. (2014) Guidelines on Urolithiasis. European Association of Urology, Arnhem.

http://www.uroweb.org/gls/pdf/\%Urolithisis_LR.pdf

[9] Itoh, Y., Kojima, Y., Yasui, T., et al. (2007) Examination of Alpha 1 Adrenoceptor Subtypes in the Human Ureter. International Journal of Urology, 14, 749-753.

https://doi.org/10.1111/j.1442-2042.2007.01812.x

[10] Seitz, C., Liatsikos, E., Porpiglia, F., Tiselius, H.G. and Zwergel, U. (2009) Medical Therapy to Facilitate the Passage of Stones: What Is the Evidence? European Urology, 56, 455-471. https://doi.org/10.1016/j.eururo.2009.06.012

[11] Pickard, J.S., Starr, K., Banks, C., et al. (2015) Medical Expulsive Therapy in Adults with Ureteric Colic: A Multicentre, Randomised, Placebo-Controlled Trial. The Lancet, 386, 341-349. https://doi.org/10.1016/S0140-6736(15)60933-3

[12] Hollingsworth, J.M., Canales, B.K., Rogers, M.A., et al. (2016) Alpha Blockers for Treatment of Ureteric Stones: Systematic Review and Meta-Analysis. BMJ, 355, 6112. https://doi.org/10.1136/bmj.i6112

[13] Campschroer, T., Zhu, Y., Duijvesz, D., et al. (2014) Alpha-Blockers as Medical Expulsive Therapy for Ureteral Stones. Cochrane Database of Systematic Reviews, No. 4, CD008509. https://doi.org/10.1002/14651858.CD008509.pub2

[14] Furyk, J.S., Chu, K., Banks, C., et al. (2016) Distal Ureteric Stones and Tamsulosin: A Double-Blind, Placebo-Controlled, Randomized, Multicenter Trial. Annals of Emergency Medicine, 67, 86-95. https://doi.org/10.1016/j.annemergmed.2015.06.001

[15] Meltzer, A.C., Hollander, J.E., Wolfson, A.B., et al. (2017) Randomized Clinical Trial of Treatment with Tamsulosin Begun in the Emergency Department to Promote Passage of Urinary Stones. Journal of Urology, 197, 604. https://doi.org/10.1016/j.juro.2017.03.068

[16] Ye, Z., Zeng, G., Yang, H., et al. (2018) Efficacy and Safety of Tamsulosin in Medical Expulsive Therapy for Distal Ureteral Stones with Renal Colic: A Multicenter, Randomized, Double-Blind, Placebo-Controlled Trial. European Urology, 73, 385-391. https://doi.org/10.1016/j.eururo.2017.10.033 